\title{
A Refined Teaching-Learning Based Optimization Algorithm for Dynamic Economic Dispatch of Integrated Multiple Fuel and Wind Power Plants
}

\author{
Umamaheswari Krishnasamy ${ }^{1}$ and Devarajan Nanjundappan ${ }^{2}$ \\ ${ }^{1}$ Department of Electronics \& Instrumentation, Karpagam College of Engineering, Coimbatore 641032, India \\ ${ }^{2}$ Department of Electrical \& Electronics Engineering, Government College of Technology, Coimbatore 641013, India
}

Correspondence should be addressed to Umamaheswari Krishnasamy; research.uma.m@gmail.com

Received 14 December 2013; Revised 8 March 2014; Accepted 8 March 2014; Published 28 April 2014

Academic Editor: Albert Victoire

Copyright (C) 2014 U. Krishnasamy and D. Nanjundappan. This is an open access article distributed under the Creative Commons Attribution License, which permits unrestricted use, distribution, and reproduction in any medium, provided the original work is properly cited.

\begin{abstract}
Dynamic economic dispatch problem (DEDP) for a multiple fuel power plant is a nonlinear and nonsmooth optimization problem when valve-point effects, multifuel effects, and ramp-rate limits are considered. Additionally wind energy is also integrated with the DEDP to supply the load for effective utilization of the renewable energy. Since the wind power may not be predicted, a radial basis function network (RBFN) is presented to forecast a one-hour-ahead wind power to plan and ensure a reliable power supply. In this paper, a refined teaching-learning based optimization (TLBO) is applied to minimize the overall cost of operation of windthermal power system. The TLBO is refined by integrating the sequential quadratic programming (SQP) method to fine-tune the better solutions whenever discovered by the former method. To demonstrate the effectiveness of the proposed hybrid TLBO-SQP method, a standard DEDP and one practical DEDP with wind power forecasted are tested based on the practical information of wind speed. Simulation results validate the proposed methodology which is reasonable by ensuring quality solution throughout the scheduling horizon for secure operation of the system.
\end{abstract}

\section{Introduction}

Dynamic economic dispatch problem (DEDP) is indispensable for real-time control of power system operation in power generation system. It comprises allocating the total electricity generation required among the available thermal and other power generating units, assuming that a unit commitment has been previously determined [1]. The prime objective is to minimize the cost of generated power subject to physical and operational constraints in the system. The overwhelming majority of published literature, however, deals with static economic dispatch; that is, the dispatch horizon is divided into periods and the dispatch is optimized period by period. On the contrary, a dynamic dispatch process can handle with this dynamic connection both by handling the ramp rate limits of generating units and by modifying the steady state costs to include the extra fuel consumption pertinent to the act of changing the delivered power [2]. Thus, the DEDP has been acknowledged as not only a more precise formulation of economic dispatch problem (EDP) but also a complicated dynamic optimization problem [3-9].

As a potential renewable energy source, the wind power has been drawing enormous consideration, as various environmental and economic apprehensions have been dramatically increased in thermal power generation system [10]. Integrating wind energy into existing power system introduces numerous challenges to the operation and planning strategies for the utilities. The fact that wind power is neither easily predictable nor dispatchable is the prime motive behind security and reliability concerns associated with wind-integrated power systems [11]. When the wind speed changes randomly, it is more suitable for power systems containing a wind power farm to adopt dynamic models. Using DEDP, it is necessary to know the output data from the wind farm at every moment 
in the optimization process. Presently, it is rather difficult to forecast the output of a wind farm. The error can be large which further increases the complexity for the DEDP to optimally share the load among the available generators [7].

Subsequently, in a power generating station, generators are possibly operated with different fuels called multiple fuel plants and when such cases exist and are supplied with multiple fuel sources then that leads to an optimization problem of determining the economic fuel to burn in a particular time horizon $[3,4]$. In the case of these generators, unlike the conventional cost function, the cost function of each unit should be presented with a few piecewise functions reflecting the effects of fuel type changes and each segment of the hybrid cost function implies some information about the type of fuel being burned or the operational characteristics of the unit. Thus, incorporating such multiple fuel plants and wind farms for DEDP makes the problem formulation practical and greatly challenging for the solution procedure to achieve a reasonable dispatch solution. Since valve-point effects are considered the fuel cost function of such generators, they will be modeled by superimposing this effect as a rectified sinusoid component into the generating unit (quadratic) fuel cost function [5]. Traditional methods like Lagrangian relaxation, gradient projection method, and so forth [3], when used to solve DEDP, suffer from myopia for nonlinear, discontinuous search spaces, leading them to less than desirable performance, often using approximations to limit complexity. When search space is particularly irregular (due to inclusion of valve-point effects), algorithms need to be highly robust to escape from premature convergence.

Over the last few years, evolutionary algorithms, such as the genetic algorithms (GA) [3], evolutionary programming (EP) [1], the simulated annealing (SA), tabu search (TS) [2], differential evolution (DE) [8], and particle swarm optimization (PSO) [6], have been used to solve ED problems. Evolutionary algorithms are appropriate choices for solving DED problems as they prove to be very effective in solving without any restrictions in the shape of the cost curves and also because of their global search ability as well as their robust and effective constraint handling capacity. Perhaps, they do not always guarantee discovering the globally optimal solution in finite time. Therefore, hybrid methods combining two or more optimization methods were introduced [13]: to name a few, hybrid fuzzy PSO and Nelder-Mead (FAPSO-NM), hybrid DE and sequential quadratic programming (DESQP), hybrid GA (HGA), evolutionary strategy optimization (ESO), self-organizing hierarchical PSO (SOHPSO), variable scaling hybrid differential evolution (VSHDE), hybrid PSO, and sequential quadratic programming (PSO-SQP) [2] and there is a large still-growing body of literature. To be concise, few are included in [14]. More precisely, hybrid methods combining probabilistic methods and deterministic methods are found to be very effective in solving complex optimization problems [2].

Recently, a new optimization technique known as teaching learning based optimization (TLBO) has been developed by Rao et al. $[15,16]$. It is one of the recent evolutionary algorithms and is based on the natural phenomenon of teaching and learning process. It has already proved its superiority over other existing optimization techniques such as GA, ABC, PSO, harmony search (HS), DE, and hybrid-PSO. This research also proposes a hybrid method combining the teaching-learning based optimization (TLBO) and SQP [17]. Here, TLBO will be performed as a base level search procedure, which makes a decision to direct the search towards the optimal region. Later the exact method (SQP) will be used to fine-tune that region to get the final solution $[4,5]$.

A practical thermal power system integrated with the wind power generation system is used to demonstrate the application of the proposed hybrid methodology. The wind power system is designed and commissioned by the Suzlon Energy, India, with an installed capacity of a $150 \mathrm{MW}(1.5 \times$ 100 mills) wind farm. This wind farm is integrated with the Load Dispatch Center at Erode (LDCE) where a thermal system comprising 7 thermal units with multiple fuel options and valve-point loading effects is controlled. Several experiments are performed to validate the effectiveness of the proposed approach.

\section{Mathematical Formulation of the DEDP}

The objective function of DEDP is to minimize the total production cost of a power system over a given dispatch period, while satisfying various constraints [2]. Mathematically the objective function is given as

$$
\text { Minimize, } \quad F_{T}=\sum_{h=1}^{H} \sum_{i=1}^{N} F_{i h}\left(P_{i h}\right) .
$$

Generally, the generator cost function is usually expressed as a quadratic polynomial as

$$
F_{i h}\left(P_{i h}\right)=a_{i} P_{i h}^{2}+b_{i} P_{i h}+c_{i} .
$$

Generators with multivalve steam turbines produce ripples like effect on their input-output curves. This effect, known as valve point effect, makes the generator cost function discontinuous and nonconvex. For accurate modeling of the cost function, the valve point effect is considered by superimposing it with the basic cost function

$$
F_{i h}\left(P_{i h}\right)=a_{i} P_{i h}^{2}+b_{i} P_{i h}+c_{i}+\left|e_{i} \sin \left(f_{i}\left(P_{i h}^{\min }-P_{i h}\right)\right)\right| .
$$

Many generating units are supplied with multiple fuel sources and the cost functions of these units are represented with a few or several piecewise quadratic functions. Such a cost function is called a hybrid cost function and each segment of the hybrid cost function gives some information about the fuel burned. The hybrid cost function is given as

$$
\begin{aligned}
& F_{i h}\left(P_{i h}\right)
\end{aligned}
$$

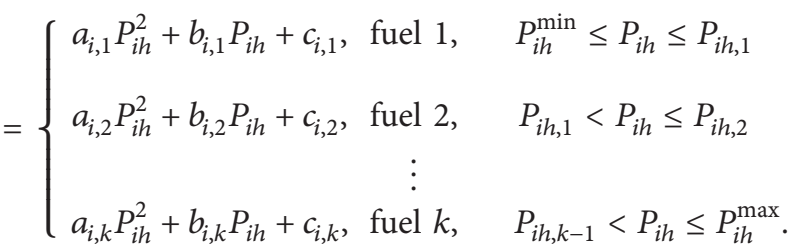


For more accurate dispatch results, the valve point effect and the multiple fuel options are integrated into the basic cost function. Thus, the basic quadratic cost function given in (2) with $N$ generating units and $N_{F}$ fuel options for each unit is given as

$$
\begin{array}{r}
F_{i h}\left(P_{i h}\right)=a_{i, k} P_{i h}^{2}+b_{i, k} P_{i h}+c_{i, k} \\
+\left|e_{i, k} \sin \left(f_{i, k}\left(P_{i h, k}^{\min }-P_{i h}\right)\right)\right|, \\
\text { if } P_{i h, k}^{\min } \leq P_{i h} \leq P_{i h, k}^{\max } \text {, fuel option } k \\
k=1,2, \ldots, N_{F} .
\end{array}
$$

The objective function as given in (1) is subject to following equality and inequality constraints.

The power output from all the generating units must satisfy the total demand and the transmission losses of the system. The equality constraint is given as

$$
\sum_{i=1}^{N} P_{i h}=P_{D h}+P_{\text {Loss }, h}
$$

The transmission loss is expressed in a quadratic form as

$$
P_{\text {Loss }, h}=\sum_{m=1}^{N} \sum_{n=1}^{N} P_{m h} B_{m n} P_{n h}
$$

The real power output of each generating unit is limited by the maximum and minimum power limit of the units. It is given as

$$
P_{i}^{\min } \leq P_{i h} \leq P_{i}^{\max }
$$

The operating range of the generating units is restricted by their ramp rate limits. This is given as

$$
\begin{array}{ll}
P_{i h}-P_{i(h-1)} \leq U R_{i} & \text { if generation increases, } \\
P_{i(h-1)}-P_{i h} \leq D R_{i} & \text { if generation decreases. }
\end{array}
$$

Thus, (8) is modified as

$$
\max \left(P_{i}^{\min }, P_{i(h-1)}-D R_{i}\right) \leq P_{i h} \leq \min \left(P_{i}^{\max }, P_{i(h-1)}+U R_{i}\right) .
$$

2.1. Accounting the Wind Power for the DEDP. Similarly, the nonlinear and fluctuation nature of wind proves to be great challenge for reliability and accuracy of power system that incorporates wind power. With accurate wind speed data, power system operator can predict the required power output. This helps in system planning, scheduling, and storage capacity optimization. To obtain proper and efficient wind power utilization wind speed prediction plays an important factor in forecasting. In the literature, several models have been used for wind speed prediction. The models are mainly physical and statistical models [18, 19]. Artificial neural network derives its computing power through its massively parallel distributed structure and its ability to learn and generalization for inputs. Neural network models have better performance than other models [12]. There are many approaches used based on neural networks such as multilayer perceptron (MLP), ADALINE, back propagation network (BPN), radial basis function network (RBFN), and recurrent neural network (RNN). This paper proposes the radial basis function network for the forecasting of wind speed subsequently with the wind power generated.

The wind power is estimated from the forecasted wind speed using the following expressions; as well known the wind power can be harvested only at a particular wind speed; thus, the wind power " $w$ " is given by

$$
\begin{aligned}
& w=0, \quad v<v_{\text {in }} \quad \text { or } \quad v>v_{\text {out }}, \\
& w=w_{R}\left(\frac{v-v_{\text {in }}}{v_{R}-v_{\text {in }}}\right), \quad v_{\text {in }} \leq v \leq v_{R}, \\
& w=w_{R}, \quad v_{R} \leq v \leq v_{\text {out }},
\end{aligned}
$$

where $w_{R}$ is the wind turbine rated power, $v$ is the actual wind speed, $v_{R}$ is the wind turbine rated wind speed, $v_{\text {in }}$ is the wind turbine cutin speed, and $v_{\text {out }}$ is the wind turbine cutout speed. Thus, (6) is rewritten as

$$
\sum_{i=1}^{N} P_{i h}+\sum_{j=1}^{m} w_{j h}=P_{D h}+P_{\text {Loss }, h}, \quad 0 \leq w_{j h} \leq w_{R},
$$

where $w_{j h}$ is the wind power generated at time $h$, and the total power generated from the entire wind farm containing " $m$ " wind mills is the summation of the wind power generated by the individual wind turbine. Thus, the DEDP will then be solved for economically dispatching the remaining demanded power using the multiple fuel power plant.

2.2. Evaluation Function. We must define the evaluation function for evaluating the fitness of each candidate in the solution space. It is the sum of the generation cost function $F_{\text {obj }}$ and power balance constraint $P_{\text {bnc }}$ as in (1) and (3).

The evaluation function is as follows:

$$
\operatorname{Min} f=F_{\mathrm{obj}}+P_{\mathrm{bnc}} \text {, }
$$

where

$$
\begin{gathered}
F_{\text {obj }}=\frac{F_{T}}{\sum_{h=1}^{H} \sum_{i=1}^{N} \Gamma_{i h}}, \\
\sum_{h=1}^{H} \sum_{i=1}^{N} \Gamma_{i h}=\frac{F_{T \max }}{F_{T \min }} .
\end{gathered}
$$

$F_{T \max }$ is the total fuel cost obtained using $P_{i h}=P_{i \max }$ and

$F_{T \text { min }}$ is the total fuel cost obtained using $P_{i h}=P_{i \text { min }}$ :

$$
P_{\mathrm{bnc}}=\left\{\sum_{h=1}^{H}\left(P_{\mathrm{Dh}}+P_{\mathrm{Loss}, h}-\left(\sum_{i=1}^{N} P_{i h}+\sum_{j=1}^{m} w_{j h}\right)\right)^{2}\right\} .
$$

In order to limit the evaluation value of each candidate of the population within a feasible range, before estimating 
the fitness value of a candidate, the generated power output must satisfy the constraint given in (8). This evaluation function will be used to find the optimum design variable value for the DEDP.

\section{Wind Power Forecasting Using the Radial Basis Function Network}

For the reason that the speed of wind is unpredictable, accurate wind speed forecasting still remains a challenging task. Accurate wind speed prediction aids grid operator to dispatch economically the wind power generated to satisfy the power demand. Wind speed predictions can mainly be done using two models called physical and statistical models. The physical model considers the physical reasoning to get the best results. The statistical model considers online measurements of data. On the other hand, statistical models are more efficient than physical models where real time data is used $[20,21]$. Artificial neural network (ANN) is one such statistical model, which derives its computing power through its massively parallel distributed structure and its ability to learn and generalization for inputs [22-24]. The choice of $\mathrm{ANN}$ is also imperative in accurate wind speed/power forecasting.

3.1. Radial Basis Function Network. Radial basis function (RBF) [12] network uses Gaussian function and has a long history in the applications of recognition and approximating function. RBF networks comprise three layers: the input layer, the hidden layer, and the output layer, where the hidden layer functions as layer of RBF units. The output layer is generally a linear function. The interconnection between input and hidden layer form hypothetical connection and between the hidden and output layers form weighted connections.

Each hidden layer unit represents a single radial basis function, with associated center position and width. Each neuron on the hidden layer employs a radial basis function as a nonlinear transfer function to operate on the input data. The most often used RBF is a Gaussian function that is characterized by a center and width. RBF functions by measuring the Euclidean distance between input vector and the radial basis function center.

The Gaussian RBF may be tuned by adjusting spread. It is less susceptible to problem with non-stationary input because of the behavior of RBF hidden units. The Gaussian function curve has a peak at zero distance and it decreases as the distance from the centre increases.

The Gaussian function is generally defined as

$$
f\left(\theta_{\mathrm{in}}\right)=e^{-\theta_{\mathrm{in}}^{2}},
$$

where $\theta_{\text {in }}$ is the net input.

The advantages of RBFN are being more compact and having less training time, while eliminating local minima phenomena. The selection of the centers for the Gaussian function is important for nonlinear approximation. The weights between the hidden and output layer is then updated using the gradient descent rule.
The RBFN design includes structural and parameter design. The structural design involves finding number of neuron. The parameter design involves spread and weight of output mode. The RBFN is much more effective tool which gains the advantage of both generalizing and refining local features over BPN:

$$
\text { Output, } \quad \phi=\sum_{k=1}^{n} f\left(\left\|\theta-C_{k}\right\|\right) * W_{i k}, \quad i=1,2, \ldots, n,
$$

where $\theta$ is input vector, " $n$ " is number of neurons, $C_{k}$ is $K$ th centre node in the hidden layer, and $W_{i k}$ is the weight between hidden and output layer.

3.2. The RBF-ANN Model for Forecasting the Wind Power. This paper proposes a new RBF network architecture for forecasting the wind power by modifying the one designed in [12]. Since the method is established as a reliable predictor of wind power, the training data used in this research are different and claimed as original contribution to ensure a more accurate prediction of wind power to assist the DEDP. The wind speed depends on temperature, pressure difference in the two different parts of the ground, wind direction, and so on. In [12], the authors used three inputs to estimate the wind speed and they are the temperature, wind direction, and the past history of wind speed. Based on the information gathered from the Suzlon Energy Ltd., India, we understand that for a particular wind speed, the temperature and wind vane directions need not be the same at all instances. Perhaps the wind speed is influenced by various other factors. Thus, in this research, unlike [12], three different data of temperature and wind vane directions for the range of wind speed are used to train the RBFN. This improves the accuracy in predicting the wind speed and thereby the wind power with a chance of increasing the reliability of the installed wind power generation.

3.2.1. Architecture. For implementing the architecture, selection of inputs, hidden neuron, and outputs are required. These selections depend on nature of the problem. The data required for inputs are wind speed, wind direction, and temperature. In spite of these three different data of temperature and wind vane directions, the same range of wind speed is used to train the RBFN. That is, for a particular wind speed there are three different data taken. This is because various other factors also influence the wind speed. Hence, training the RBFN with additional data for the same wind speed increases the prediction of wind speed. This improves the accuracy in predicting the wind speed and thereby the wind power with a chance of increasing the reliability of the installed wind power generation. Neural network with one hidden layer with a sufficient number of hidden neuron is capable of approximating any continuous function. The basic architecture is shown in Figure 1.

The sample of the collected data as shown in Figures 2 and 3 are used as input to the RBFN model. A large number of input parameters can be used for the analysis of the NN models. The input parameters are three different temperatures, 


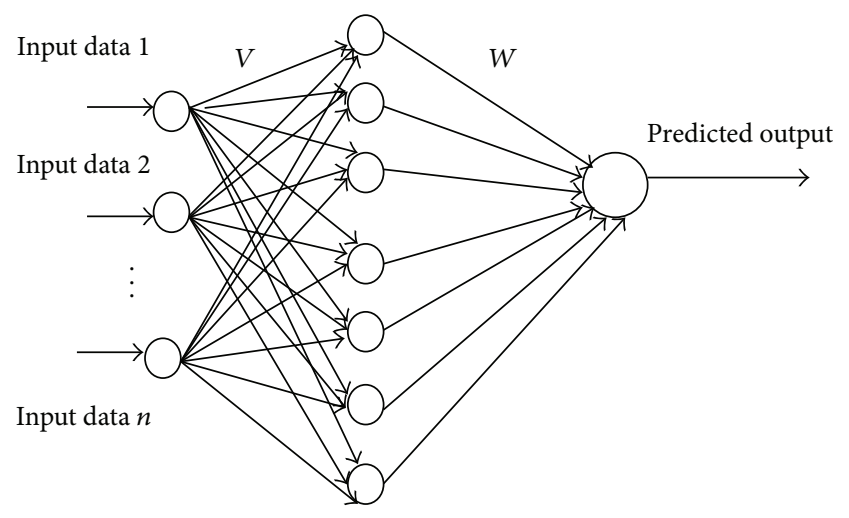

Input layer Hidden layer Output layer

FIgURE 1: The RBF-ANN architecture.

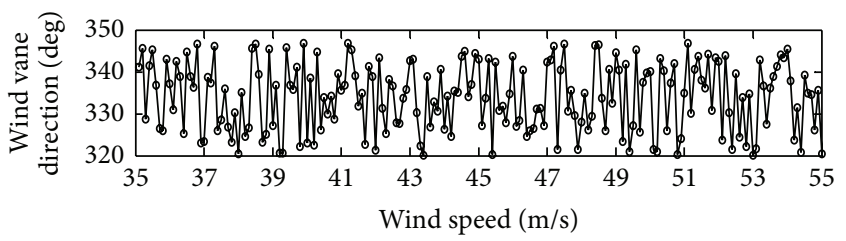

(a)

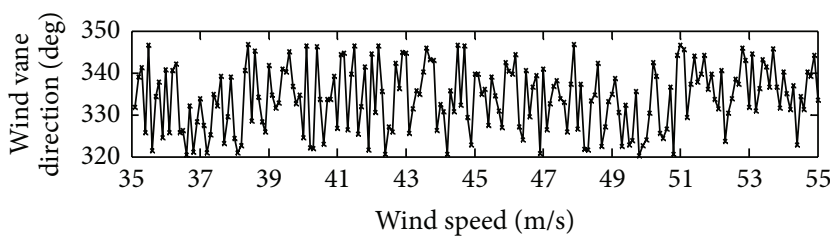

(b)

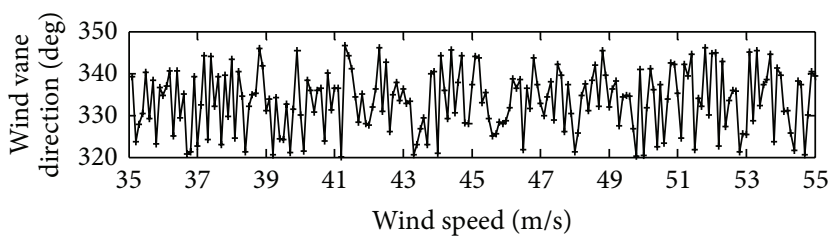

(c)

FIGURE 2: Samples of wind vane direction and wind speeds.

three different wind directions, and the corresponding past wind speed. The inputs are analyzed in different heights $(50 \mathrm{~m}$ and $65 \mathrm{~m}$ ) of wind mills. The analysis of $\mathrm{NN}$ architecture is utilized with $500,1000,2000,5000$, and 10000 data for training and testing of model.

The selection of hidden neurons is very important. Based on trial and error method, 7 hidden neurons are selected with single hidden layer. The constructed architecture includes single hidden layer with 7 hidden neurons, 3 inputs, and 1 output for implementing the model and initializing the weights and epochs. The performance can change by increasing the epochs. The weights are calculated by using gradient descent rule. The error is the difference between actual and target value. The errors are minimized by adjusting the weights.

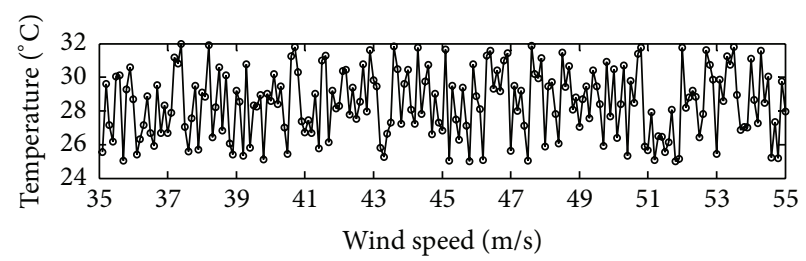

(a)

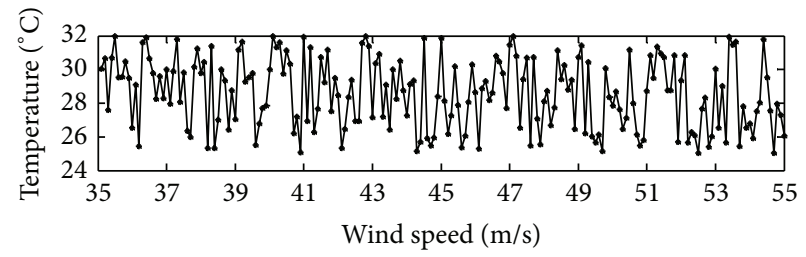

(b)

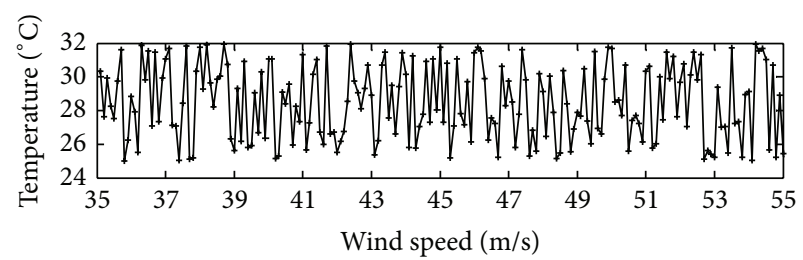

(c)

FIGURE 3: Samples of temperature and wind speeds.

TABLE 1: Input parameters of the proposed models.

\begin{tabular}{lccc}
\hline S. number & Input parameters & Units & Range of the parameters \\
\hline 1 & Wind speed & $\mathrm{m} / \mathrm{s}$ & $35-55$ \\
2 & Wind direction & $\circ$ & $320-347$ \\
3 & Temperature & ${ }^{\circ} \mathrm{C}$ & $24-32$ \\
4 & Installed wind power & $\mathrm{MW}$ & $100 \times 1.5 \mathrm{MW}(150 \mathrm{MW})$ \\
\hline
\end{tabular}

\subsubsection{Methodology}

Step 1 (data collection). The real time data is collected from Suzlon Energy Ltd., India, wind farm. The inputs are wind speed, wind direction, and temperature. The predicted wind speed is an output of the proposed model. The number of samples taken to develop a proposed model is 500, 1000, 2000, 5000, and 10000. The input parameters are as shown in Table 1 . The wind energy depends on wind speed, wind direction, and temperature.

Step 2 (data normalization). The data normalization is carried out to improve accuracy of subsequent numeric computation and to obtain better output of model. The min max technique is used for normalization of input data. The advantage is preserving exactly all relationships in the data and it does not introduce bias. The normalization of data is obtained by the following.

Normalized input is as follows:

$$
\phi_{i}^{\prime}=\left(\frac{\phi_{i}-\phi_{\min }}{\phi_{\max }-\phi_{\min }}\right)\left(\phi_{\max }^{\prime}-\phi_{\min }^{\prime}\right)+\phi_{\min }^{\prime},
$$


TABle 2: Parameter selection for designing the various networks.

\begin{tabular}{lccc}
\hline Parameters & BPN [12] & RBFN [12] & Improved RBFN \\
\hline Learning rate & 0.25 & 0.8 & 0.8 \\
Momentum factor & 0.9 & - & 7 \\
Number of neurons in hidden layer & 7 & 3 & 7 \\
Inputs & 3 & 2000 & 2000 \\
Epochs & 2000 & Newrb & Newrb \\
Training function & Trainlm & Gaussian function & Gaussian function \\
Activation function & Sigmoid function
\end{tabular}

where $\phi_{i}, \phi_{\min }, \phi_{\max }$ are the actual input data and minimum and maximum input data. $\phi_{\min }^{\prime}, \phi_{\max }^{\prime}$ are the minimum and maximum target values.

Step 3 (designing the neural network). Setup parameter includes learning rate, epoch, and dimensions. The training can be learned from the past data after normalization. The dimensions like number of input, hidden, and output neurons are to be initialized. The three input parameters are temperature, wind direction, and wind speed. The number of hidden layers is one. The number of hidden neurons is selected based on trial and error method. The input signal is processed and net input of model is computed. The net input is the weighted sum of inputs. The activation function is applied over the net input to calculate the output of neural network model. The sample inputs that are applied into the proposed model are as shown in Table 2. The sample inputs used for design of neural network are shown in Table 3.

Step 4 (training of network). For the purpose of developing models, the training, testing, and developing model at end stage for the past years in wind farms are needed. The data required for input are wind speed, wind direction, and temperature. Here, $70 \%$ of the total data is used for training the network.

Step 5 (testing of network). Evaluate the performance of network by testing models. Here, all available data is used for testing the network. Finally the predicted wind speed is the output of the NN architectures.

Thus, the RBF network is used to predict the wind speed from the past data and thereby the wind power. Once the wind speed is predicted, the wind power is estimated using the expression given in (11). Once the available wind power is estimated for the given horizon, the DEDP is solved to economically dispatch remaining power demand with the multiple fuel plant. This solves the DEDP using the teachinglearning based optimization refined using the sequential quadratic programming method which is discussed in the following section.

\section{Teaching-Learning Based Optimization}

Teaching-learning based optimization (TLBO) is an optimization technique developed by Rao et al. [15, 16] based on teaching-learning process in a class among the teacher
TABle 3: Typical sample inputs and wind speed for a 24-hour horizon (data provided by Suzlon Energy Ltd).

\begin{tabular}{lccc}
\hline Hour & Temp. $\left({ }^{\circ} \mathrm{C}\right)$ & $\begin{array}{c}\text { Wind vane direction } \\
\text { from true north }\left({ }^{\circ}\right)\end{array}$ & $\begin{array}{c}\text { Wind speed } \\
(\mathrm{m} / \mathrm{sec})\end{array}$ \\
\hline 1 & 23.5 & 283.1 & 36.3 \\
2 & 23.9 & 285.7 & 36.8 \\
3 & 23.1 & 284.0 & 36.5 \\
4 & 24.9 & 283.6 & 37.2 \\
5 & 24.1 & 284.6 & 37.5 \\
6 & 23.8 & 282.7 & 37.3 \\
7 & 24.0 & 283.8 & 42.7 \\
8 & 24.6 & 284.4 & 48.2 \\
9 & 25.8 & 282.9 & 48.6 \\
10 & 27.7 & 282.7 & 50.7 \\
11 & 27.6 & 284.0 & 48.7 \\
12 & 28.1 & 285.3 & 48.9 \\
13 & 27.9 & 285.5 & 52.7 \\
14 & 29.0 & 283.4 & 48.8 \\
15 & 30.2 & 283.1 & 48.9 \\
16 & 27.4 & 285.2 & 45.6 \\
17 & 25.9 & 283.3 & 42.6 \\
18 & 24.1 & 284.6 & 41.7 \\
19 & 23.2 & 285.6 & 39.6 \\
20 & 23.9 & 284.7 & 37.3 \\
21 & 23.4 & 285.3 & 36.8 \\
22 & 23.4 & 282.6 & 36.4 \\
23 & 23.5 & 283.0 & \\
24 & 23.9 & 285.2 & \\
\hline & & & 3.9 \\
\hline
\end{tabular}

TABLE 4: Comparison of MSE for various approaches.

\begin{tabular}{lcc}
\hline S. number & Comparison of approaches & MSE $(\mathrm{m} / \mathrm{s})$ \\
\hline 1 & BPN [12] & 0.397 \\
2 & RBFN [12] & 0.133 \\
3 & Proposed improved RBFN & 0.092 \\
\hline
\end{tabular}

and the students. Like other nature-inspired algorithms, TLBO is also a population based technique with a predefined population size that uses the population of solutions to arrive at the optimal solution. In this method, population is also called students in a class and design variables are the subjects 
TABLE 5: Wind power (for a particular trial) estimated from the wind farm for the predicted wind speed.

\begin{tabular}{|c|c|c|c|}
\hline Hour & $\begin{array}{c}\text { Actual wind } \\
\text { power (Suzlon) } \\
(\mathrm{MW})\end{array}$ & $\begin{array}{l}\text { Naive method } \\
\quad(\mathrm{MW})\end{array}$ & $\begin{array}{l}\text { IRBF method } \\
(\mathrm{MW})\end{array}$ \\
\hline 1 & 129.9336 & 126.287 & 131.317 \\
\hline 2 & 130.5483 & 134.9044 & 131.5846 \\
\hline 3 & 129.6927 & 131.612 & 131.3064 \\
\hline 4 & 130.3383 & 133.7114 & 130.5666 \\
\hline 5 & 130.5251 & 127.5346 & 128.5235 \\
\hline 6 & 130.5604 & 130.0561 & 130.8185 \\
\hline 7 & 132.4563 & 128.202 & 133.6588 \\
\hline 8 & 140.1752 & 143.6834 & 142.0634 \\
\hline 9 & 142.3433 & 142.9024 & 141.182 \\
\hline 10 & 144.4042 & 142.5835 & 145.2115 \\
\hline 11 & 146.2464 & 144.9367 & 146.2729 \\
\hline 12 & 146.9441 & 146.5454 & 148.6656 \\
\hline 13 & 146.443 & 145.1807 & 147.2728 \\
\hline 14 & 147.0039 & 142.7703 & 145.9053 \\
\hline 15 & 144.1318 & 141.0621 & 143.8849 \\
\hline 16 & 141.6287 & 137.0738 & 140.2092 \\
\hline 17 & 134.4697 & 135.0275 & 136.2793 \\
\hline 18 & 134.4699 & 130.65 & 133.8301 \\
\hline 19 & 132.3468 & 132.5606 & 130.4664 \\
\hline 20 & 132.2144 & 128.3965 & 133.237 \\
\hline 21 & 131.5594 & 134.1488 & 133.032 \\
\hline 22 & 130.1897 & 128.819 & 129.2422 \\
\hline 23 & 130.3156 & 133.5282 & 129.387 \\
\hline 24 & 130.1835 & 125.598 & 131.8266 \\
\hline
\end{tabular}

taken up by the students. Each candidate solution comprises design variables responsible for the knowledge scale of a student and the objective function value symbolizes the knowledge of a particular student. The solution having best fitness in the population (among all students) is considered the teacher.

More specifically, an individual student $\left(X_{i}\right)$ within the population represents a single possible solution to a particular optimization problem. $X_{i}$ is a real-valued vector with $D$ elements, where $D$ is the dimension of the problem and is used to represent the number of subjects that an individual, either student or teacher, enrolls to learn/teach in the TLBO context. The algorithm then tries to improve certain individuals by changing these individuals during the teacher and learner phases, where an individual is only replaced if his/her new solution is better than his/her previous one. The algorithm will repeat itself until it reaches the maximum number of generations.

During the teacher phases, the teaching role is assigned to the best individual $\left(X_{\text {teacher }}\right)$. The algorithm attempts to improve other individuals $\left(X_{i}\right)$ by moving their position towards the position of the $X_{\text {teacher }}$ by referring the current mean value of the individuals $\left(X_{\text {mean }}\right)$. This is constructed
TABLE 6: Production cost obtained using the proposed hybrid TLBO-SQP method for each hour for Case 2 .

\begin{tabular}{lc}
\hline Hour & Hourly cost $(\$)$ \\
\hline 1 & 28245.17821 \\
2 & 29831.86233 \\
3 & 33143.03628 \\
4 & 36303.70371 \\
5 & 37909.09501 \\
6 & 41395.27309 \\
7 & 42711.98083 \\
8 & 44452.70101 \\
9 & 48000.5086 \\
10 & 51963.15329 \\
11 & 53892.34991 \\
12 & 55871.06585 \\
13 & 51375.66738 \\
14 & 47970.41675 \\
15 & 44605.33395 \\
16 & 39887.21366 \\
17 & 37915.15738 \\
18 & 41283.82856 \\
19 & 44360.70332 \\
20 & 51792.13042 \\
21 & 47727.3719 \\
22 & 41517.72629 \\
23 & 35037.89283 \\
24 & 31477.24481 \\
\hline
\end{tabular}

using the mean values for each parameter within the problem space (dimension) and represents the qualities of all students from the current generation. Equation (1) simulates how student improvement may be influenced by the difference between the teacher's knowledge and the qualities of all students. For stochastic purposes, randomly generated parameters are applied within the equation: $r$ ranges between 0 and 1 and $T_{F}$ is a teaching factor which can be either 1 or 2 , thus emphasizing the importance of student quality:

$$
X_{\text {new }}=X_{i}+r \cdot\left(X_{\text {teacher }}-\left(T_{F} \cdot X_{\text {mean }}\right)\right) .
$$

During the learner phase, student $\left(X_{i}\right)$ tries to improve his/her knowledge by peer learning from an arbitrary student $X_{i i}$, where $i$ is unequal to $i i$. In the case that $X_{i i}$ is better than $X_{i}, X_{i}$ moves towards $X_{i i}(20)$. Otherwise, it is moved away from $X_{i i}$ (21). If student $X_{\text {new }}$ performs better by following (20) or (21), he/she will be accepted into the population. The algorithm will continue its iterations until reaching the maximum number of generations:

$$
\begin{aligned}
& X_{\text {new }}=X_{i}+r \cdot\left(X_{i i}-X_{i}\right), \\
& X_{\text {new }}=X_{i}+r \cdot\left(X_{i}-X_{i i}\right) .
\end{aligned}
$$

Additionally infeasible individuals must be appropriately handled to determine whether one individual is better than the other, when applied to constrained optimization problems. For comparing two individuals, the TLBO algorithm, 
TABLE 7: Summary of best, worst, and mean production cost produced by the various methods for Case 2.

\begin{tabular}{lccccc}
\hline Method & Maximum cost $(\$)$ & Minimum cost $(\$)$ & Average cost $(\$)$ & Average time $(\mathrm{min})$ & Minimum time $(\mathrm{min})$ \\
\hline TLBO & 1037842 & 1031746 & 1035748 & 5.62 & 5.21 \\
CSADHS & 1018760 & 1018681 & 1018718 & 2.72 & 2.63 \\
TLBO-SQP & 1018842 & 1018679 & 1018702 & 2.61 & \\
\hline
\end{tabular}

TABLE 8: Data for the 7-unit practical system with multiple fuel cost coefficient.

\begin{tabular}{|c|c|c|c|c|c|c|c|c|c|}
\hline \multirow{3}{*}{ Unit } & \multicolumn{3}{|c|}{ Generation } & \multirow{3}{*}{ Fuel type } & \multirow{2}{*}{\multicolumn{5}{|c|}{ Cost coefficient }} \\
\hline & \multirow{2}{*}{\multicolumn{3}{|c|}{$\begin{array}{lccc}\text { Min } & \text { P1 } & \text { P2 } & \text { max } \\
\text { F1 } & \text { F2 } & \text { F3 }\end{array}$}} & & & & & & \\
\hline & & & & & $a_{i}$ & $b_{i}$ & $c_{i}$ & $e_{i}$ & $f_{i}$ \\
\hline \multirow{3}{*}{1} & \multirow{3}{*}{\multicolumn{3}{|c|}{$\begin{array}{rrrr}50 & 114 & 157 & 230 \\
1 & 2 & 3\end{array}$}} & 1 & $0.1184 e 3$ & $-0.1269 e 1$ & $0.4194 e-2$ & $0.1184 e 0$ & $-0.1269 e 2$ \\
\hline & & & & 2 & $0.1865 e 1$ & $-0.3988 e-1$ & $0.1138 e-2$ & $0.1865 e-2$ & $-0.3988 e 0$ \\
\hline & & & & 3 & $0.1365 e 2$ & $-0.1980 e 0$ & $0.1620 e-2$ & $0.1365 e-1$ & $-0.1980 e 1$ \\
\hline \multirow{3}{*}{2} & \multirow{3}{*}{\multicolumn{2}{|c|}{$\begin{array}{lc}200 & 332 \\
1 & 2\end{array}$}} & \multirow{3}{*}{$\begin{array}{cc}388 & 500 \\
3 & \end{array}$} & 1 & $0.3979 e 2$ & $-0.3116 e 0$ & $0.1457 e-2$ & $0.3979 e-1$ & $-0.3116 e 1$ \\
\hline & & & & 2 & $-0.5914 e 2$ & $0.4864 e 0$ & $0.1176 e-4$ & $-0.5914 e-1$ & $0.4864 e 1$ \\
\hline & & & & 3 & $-0.2875 e 1$ & $0.3389 e-1$ & $0.8035 e-3$ & $-0.2876 e-2$ & $0.3389 e 0$ \\
\hline \multirow{3}{*}{3} & \multirow{3}{*}{\multicolumn{3}{|c|}{$\begin{array}{lrrr}99 & 138 & 200 & 265 \\
1 & 2 & 3 & \end{array}$}} & 1 & $0.1983 e 1$ & $-0.3114 e-1$ & $0.1049 e-2$ & $0.1983 e-2$ & $-0.3114 e 0$ \\
\hline & & & & 2 & $0.5285 e 2$ & $-0.6348 e 0$ & $0.2785 e-2$ & $0.5285 e-1$ & $-0.6348 e 1$ \\
\hline & & & & 3 & $0.2668 e 3$ & $-0.2338 e 1$ & $0.5935 e-2$ & $0.2668 e 0$ & $-0.2338 e 2$ \\
\hline \multirow{3}{*}{4} & \multirow{3}{*}{\multicolumn{2}{|c|}{$\begin{array}{lc}190 & 338 \\
1 & 2\end{array}$}} & \multirow{3}{*}{$\begin{array}{rr}407 & 490 \\
3 & \end{array}$} & 1 & $0.1392 e 2$ & $-0.8733 e-1$ & $0.1066 e-2$ & $0.1392 e-1$ & $-0.8733 e 0$ \\
\hline & & & & 2 & $0.9976 e 2$ & $-0.5206 e 0$ & $0.1597 e-3$ & $0.9976 e-1$ & $-0.5206 e 1$ \\
\hline & & & & 3 & $-0.5399 e 2$ & $0.4462 e 0$ & $0.1498 e-3$ & $0.5399 e-1$ & $0.4462 e 1$ \\
\hline \multirow{3}{*}{5} & \multirow{3}{*}{\multicolumn{2}{|c|}{$\begin{array}{lr}85 & 138 \\
1 & 2\end{array}$}} & \multirow{3}{*}{$\begin{array}{c}200 \\
3\end{array}$} & 1 & $0.5285 e 2$ & $-0.6348 e 0$ & $0.2758 e-2$ & $0.5285 e-1$ & $-0.6348 e 1$ \\
\hline & & & & 2 & $0.1983 e 1$ & $-0.3114 e-1$ & $0.1049 e-2$ & $0.1983 e-2$ & $-0.3114 e 0$ \\
\hline & & & & 3 & $0.2668 e 3$ & $-0.2338 e 1$ & $0.5935 e-2$ & $0.2668 e 0$ & $-0.2338 e 2$ \\
\hline \multirow{3}{*}{6} & \multirow{3}{*}{\multicolumn{2}{|c|}{$\begin{array}{cc}200 & 331 \\
1 & 2\end{array}$}} & \multirow{3}{*}{$\begin{array}{r}391500 \\
3\end{array}$} & 1 & $0.1893 e 2$ & $-0.1325 e 0$ & $0.1107 e-2$ & $0.1893 e-1$ & $-0.1325 e 1$ \\
\hline & & & & 2 & $0.4377 e 2$ & $-0.2267 e 0$ & $0.1165 e-2$ & $0.4377 e-1-$ & $-0.2267 e 1$ \\
\hline & & & & 3 & $-0.4335 e 2$ & $0.3559 e 0$ & $0.2454 e-3$ & $0.4335 e-1$ & $0.3559 e 1$ \\
\hline \multirow{3}{*}{7} & \multirow{3}{*}{\multicolumn{2}{|c|}{$\begin{array}{cc}130 & 213 \\
1 & 2\end{array}$}} & \multirow{3}{*}{$\begin{array}{rr}370 & 400 \\
3 & \end{array}$} & 1 & $0.8853 e 2$ & $-0.5675 e 0$ & $0.1554 e-2$ & $0.8853 e-1$ & $-0.5675 e 1$ \\
\hline & & & & 2 & $0.1530 e 2$ & $-0.4514 e-1$ & $0.7033 e-3$ & $0.1423 e-1$ & $-0.1817 e 0$ \\
\hline & & & & 3 & $0.1423 e 2$ & $-0.1817 e-1$ & $0.6121 e-3$ & $0.1423 e-1$ & $-0.1817 e 0$ \\
\hline
\end{tabular}

according to [15], utilizes Deb's constrained handling method [25]:

(i) if both individuals are feasible, the fitter individual (with the better value of fitness function) is preferred;

(ii) if one individual is feasible and the other one infeasible, the feasible individual is preferred;

(iii) if both individuals are infeasible, the individual having the smaller number of violation (this value is obtained by summing all the normalized constraint violations) is preferred.

\section{Sequential Quadratic Programming [17]}

Sequential quadratic programming (SQP) [17] method belongs to the most powerful nonlinear programming algorithms for constrained optimization. Its excellent numerical performance was tested and compared with other nonlinear programming methods and since many years it belongs to the most frequently used algorithms to solve practical constrained optimization problems [17]. The method resembles closely Newton's method for constrained optimization just as is done for unconstrained optimization. At each iteration an approximation is made of the Hessian of the Lagrangian function using a Broyden-Fletcher-Goldfarb-Shanno quasiNewton updating method. This is then used to generate a quadratic programming subproblem whose solution is used to form a search direction for a line search procedure. The SQP subroutine for the EDP is adopted as it is in [17].

\section{The Pseudo Code of the Proposed Refined TLBO Algorithm}

The following steps enumerate the step-by-step procedure of the teaching-learning based optimization algorithm refined using the sequential quadratic programming method. 
TABle 9: Power demand for Case 3.

\begin{tabular}{lc}
\hline $\mathrm{Hr}$ & Power demand (MW) \\
\hline 1 & 1567 \\
2 & 1567 \\
3 & 1510 \\
4 & 1510 \\
5 & 1627 \\
6 & 2029 \\
7 & 2187 \\
8 & 2334 \\
9 & 2388 \\
10 & 2274 \\
1 & 2106 \\
12 & 2050 \\
13 & 1873 \\
14 & 1500 \\
15 & 1440 \\
16 & 1601 \\
17 & 1759 \\
18 & 1802 \\
19 & 2122 \\
20 & 2040 \\
21 & 1928 \\
22 & 1867 \\
23 & 1726 \\
24 & 1653 \\
\hline
\end{tabular}

(1) Initialize the number of students (population), range of design variables, iteration count, and termination criterion.

(2) Randomly generate the students using the design variables.

(3) Evaluate the fitness function using the generated (new) students.

\section{//teacher phase//}

(4) Calculate the mean of each design variable in the problem.

(5) Identify the best solution as teacher amongst the students based on their fitness value. Use SQP method to fine-tune the teacher.

(6) Modify all other students with reference to the mean of the teacher identified in step 4.

\section{//learner phase//}

(7) Evaluate the fitness function using the modified students in step 6.

(8) Randomly select any two students and compare their fitness. Modify the student whose fitness value is better than the other and use again the SQP method to fine-tune the modified student. Reject the unfit student.
(9) Replace the student fitness and its corresponding design variable.

(10) Repeat (test equal to the number of students) step 8, until all the students participate in the test, ensuring that no two students (pair) repeat the test.

(11) Ensure that the final modified students' strength equals the original strength, ensuring there is no duplication of the candidates.

(12) Check for termination criterion and repeat from step 4.

The above procedure is used to solve the DEDP once the wind power is forecasted by the RBF network. Here the SQP method will be used to fine-tune the improving (better fitness) solution. This will ensure that the better solution region will not be overrun and will also aid in converging faster towards the possible best solution of the DEDP.

\section{Numerical Experiments}

This paper establishes the effectiveness of the proposed solution methodology for DEDP with integrated wind power by solving the following test systems as three different cases:

(i) predicting the wind speed using RBFN using the data (wind speed, wind direction, and temperature, as shown in Figures 2 and 3) for a particular day (07 March, 2013; Thursday) provided by Suzlon Energy Ltd., for validating the prediction of wind speed;

(ii) solving a standard 10-unit DEDP using the proposed TLBO-SQP to validate the superiority of the method over other existing methods in the literature (this is because the literature review shows that there is not a single paper archived (as per web of knowledge) for DEDP with multiple fuel option considered);

(iii) solving a practical 7-unit multifuel DEDP with predicted wind power to share the total load demand on the DEDP (this is to validate the combined performance of the RBFN and the hybrid TLBO-SQP methodologies).

The proposed technique has been implemented in Matlab on a dual-core PC. The performance of the algorithm has been evaluated through simulation. Simulation studies have been carried out on three example test cases, over a scheduling time horizon of 24 hours.

7.1. Case 1: Wind Power Predictions. The data for the wind power prediction is provided by the Suzlon Energy Ltd., India, as they play key role in predicting the wind power for the Load Dispatch Centre, Erode, (LDCE) which is controlling the Neyveli Thermal Power Station (NTPS). The wind farm consists of 100 wind turbines of $1.5 \mathrm{MW}$ each. The LDCE forecasts wind power using Naive method as a generalized method for further scheduling the thermal units to fulfill the balance power demand requirements. Tables 1 and 2 present the training parameters for the back propagation network, RBF network, and improved RBF network. 
TABLE 10: Optimum power generation schedule by the proposed hybrid method for Case 3.

\begin{tabular}{|c|c|c|c|c|c|c|c|}
\hline Hours & Unit $1(\mathrm{MW})$ & Unit 2 (MW) & Unit 3 (MW) & Unit 4 (MW) & Unit 5 (MW) & Unit 6 (MW) & Unit 7 (MW) \\
\hline 1 & 50.1765 & 246.7831 & 109.0714 & 200.9432 & 249.4944 & 449.1239 & 130.4074 \\
\hline 2 & 50.4837 & 246.7862 & 109.1178 & 199.1263 & 249.5121 & 449.1726 & 130.802 \\
\hline 3 & 50.1504 & 248.194 & 109.6522 & 199.4125 & 250.1078 & 391.3154 & 130.167 \\
\hline 4 & 50.1504 & 248.194 & 109.6522 & 199.4125 & 250.1078 & 391.3154 & 130.167 \\
\hline 5 & 50.908 & 248.4653 & 227.0444 & 199.8768 & 249.217 & 391.8057 & 130.6821 \\
\hline 6 & 50.0372 & 248.1954 & 228.4242 & 299.0385 & 149.3936 & 491.269 & 431.6421 \\
\hline 7 & 150.5531 & 248.7201 & 228.4164 & 301.6176 & 201.7853 & 491.6717 & 430.2354 \\
\hline 8 & 150.7471 & 248.0315 & 227.6193 & 399.1701 & 250.0372 & 491.3144 & 425.0805 \\
\hline 9 & 201.5881 & 248.3894 & 227.8767 & 399.7394 & 251.8601 & 491.65 & 425.8968 \\
\hline 10 & 200.3487 & 248.5601 & 227.2035 & 284.7149 & 250.8383 & 491.8086 & 425.5268 \\
\hline 11 & 150.5375 & 248.871 & 227.0273 & 284.2595 & 250.607 & 423.3105 & 375.3871 \\
\hline 12 & 151.3938 & 248.0096 & 227.9976 & 230.6298 & 250.0504 & 416.2553 & 376.6628 \\
\hline 13 & 111.3893 & 206.308 & 187.8105 & 230.437 & 249.5497 & 366.5767 & 373.9281 \\
\hline 14 & 50.2451 & 245.2532 & 109.4874 & 198.5244 & 170.4322 & 449.9621 & 130.0953 \\
\hline 15 & 50.1059 & 245.8208 & 109.1871 & 198.0508 & 169.5593 & 393.1648 & 130.1121 \\
\hline 16 & 51.0341 & 248.0319 & 223.3174 & 198.2213 & 249.7542 & 360.2424 & 130.3985 \\
\hline 17 & 101.8185 & 249.2257 & 224.2334 & 199.0557 & 250.7762 & 404.5432 & 193.3477 \\
\hline 18 & 100.222 & 248.4538 & 223.2834 & 198.7258 & 247.2119 & 400.2288 & 249.8746 \\
\hline 19 & 150.8142 & 249.054 & 223.5754 & 280.419 & 247.8311 & 420.097 & 420.2097 \\
\hline 20 & 151.1352 & 248.5349 & 223.1048 & 230.6187 & 247.3284 & 385.2221 & 421.0556 \\
\hline 21 & 151.3026 & 248.153 & 221.6068 & 201.726 & 240.4372 & 331.1033 & 400.6704 \\
\hline 22 & 151.7401 & 246.2078 & 220.066 & 201.0327 & 190.4418 & 326.2747 & 402.2377 \\
\hline 23 & 151.2091 & 245.8827 & 220.6052 & 200.645 & 191.2556 & 285.387 & 302.0158 \\
\hline 24 & 150.6131 & 241.54 & 200.1566 & 200.9639 & 190.7316 & 286.3282 & 250.6668 \\
\hline
\end{tabular}

TABLE 11: Summary of best, worst, and mean production cost produced by the various methods for Case 2.

\begin{tabular}{lccccc}
\hline Method & Maximum cost $(\$)$ & Minimum cost $(\$)$ & Average cost $(\$)$ & Average time $(\min )$ & Minimum time $(\mathrm{min})$ \\
\hline TLBO & 9952.2471 & 9736.1471 & 9754.2321 & 4.21 & 4.18 \\
TLBO-SQP & 9588.2141 & 9538.1851 & 9551.3271 & 2.53 & 2.51 \\
\hline
\end{tabular}

Additionally Table 3 shows the typical sample inputs and wind speed for a 24-hour horizon which is used by the BPN and RBFN [12], for predicting the wind speed. Similarly Figures 2 and 3 show the samples of the training data for the improved RBF network proposed in this research, which is claimed as the new proposal to predict the wind speed as far as this research is concerned. Figure 4 shows the wind speed predicted for 100 trials by the proposed RBFN method for a 24-hour horizon. This shows that the proposed RBFN predicts almost the reasonable and acceptable wind speed (thereby wind power) throughout all the trials.

In order to find the most suited $\mathrm{NN}$ architecture, mean square error (MSE) criteria are used. MSE as one of the error indices is used for the evaluation of performance of the networks chosen in this research and is given by

$$
\operatorname{MSE}=\frac{1}{N} \sum_{i=1}^{N}\left(\theta_{i}-\theta_{i}^{\prime}\right)^{2},
$$

where $\theta_{i}$ is predicted output, $\theta_{i}^{\prime}$ is actual output, and $N$ is number of samples. The MSE is used as the criteria for measuring the forecasting performance.

The best suit NN architecture is preferred based on the accuracy of the prediction of wind power. The model accuracy is evaluated by comparing simulation results with actual/measured wind speed at the wind farm by the Suzlon. The experiments were carried out to test the performance of the improved RBF in comparison with that of BPN and RBFN [12]. Based on the MSE summarized in Table 4, the improved RBFN proposed in this research proves predicting reasonably closer wind speed prediction than other methods. It is demonstrated that proposed improved RBFN is more accurate than other networks and found suitable for wind speed prediction in wind farms.

Figure 5 shows the comparison plot of the wind speed predicted by various methods for a 24-hour scheduling horizon, where the proposed improved RBFN is very much closely following the actual wind speed. Finally, Table 5 shows 

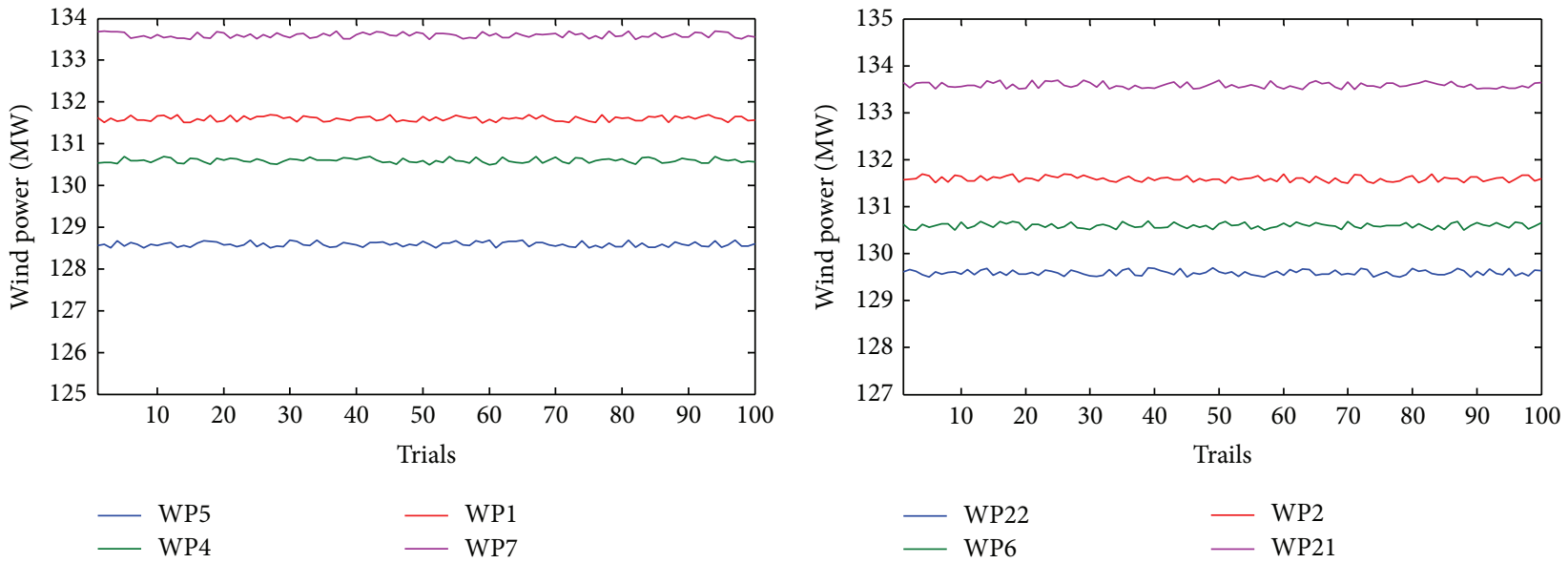

(a)
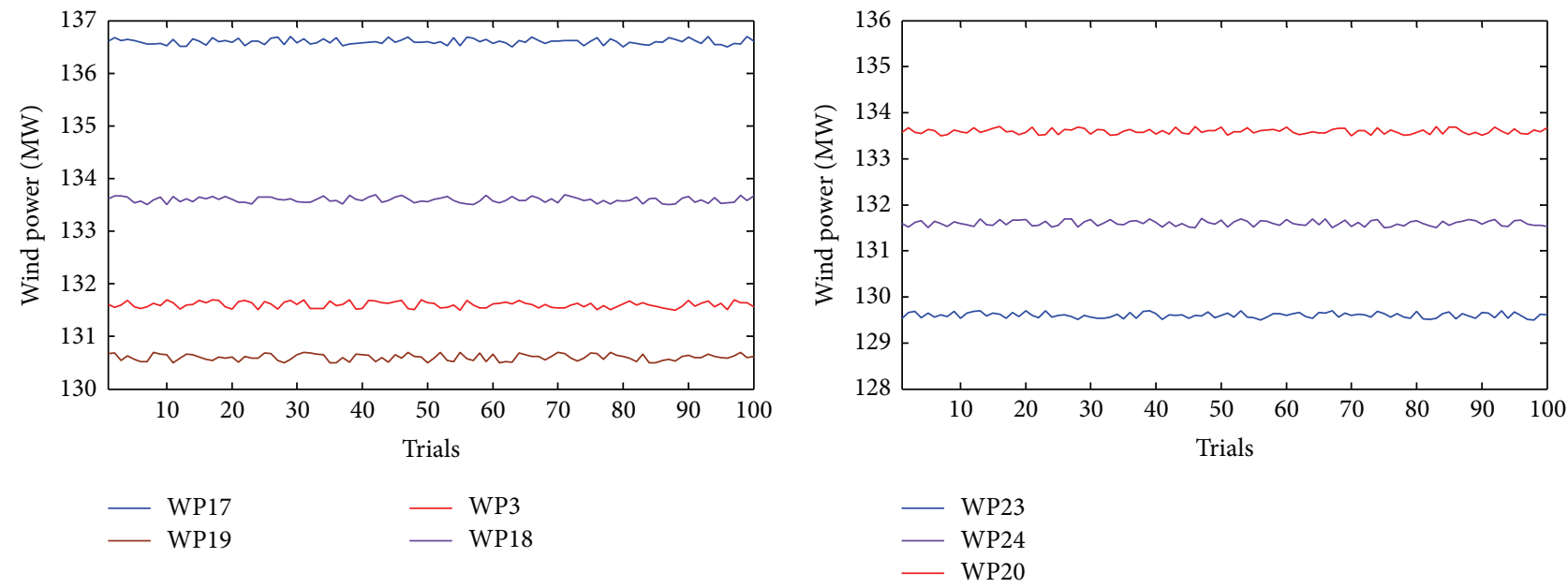

(c)
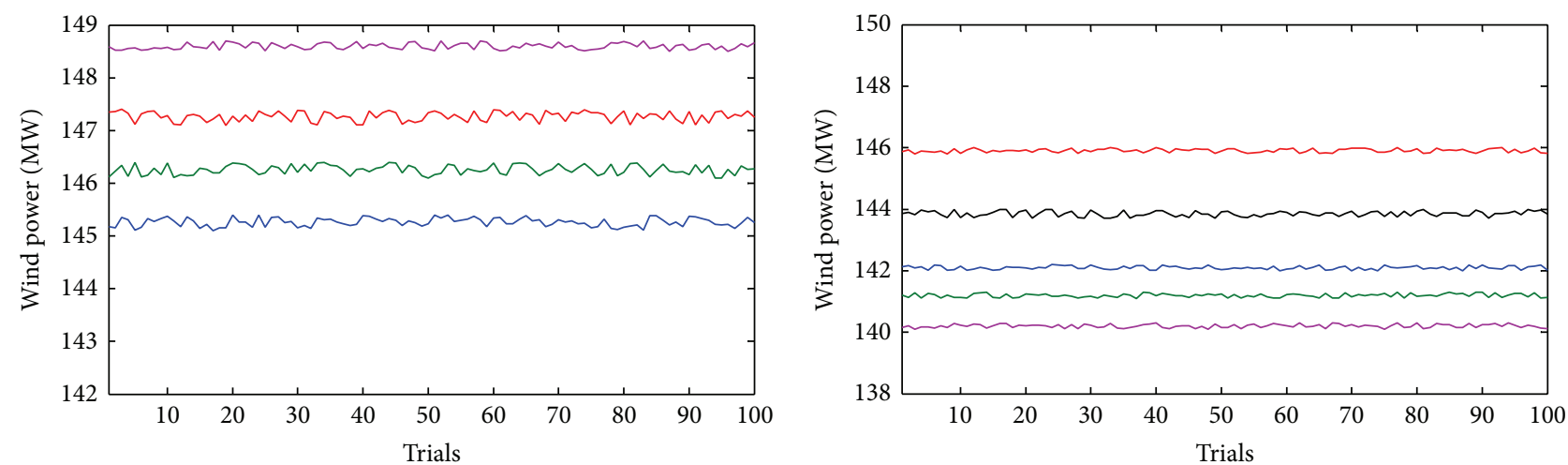

$\begin{array}{ll}\text { WP10 } & \text { WP12 } \\ \text { WP11 } & \text { WP13 }\end{array}$

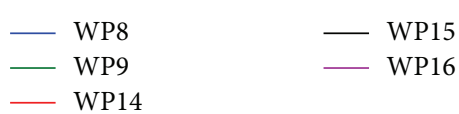

(e)

(f)

FIGURE 4: Wind speed predicted for 100 trials by the proposed IRBFN method for a 24-hour horizon (legend WP (hr) stands for wind power at that particular hour). 


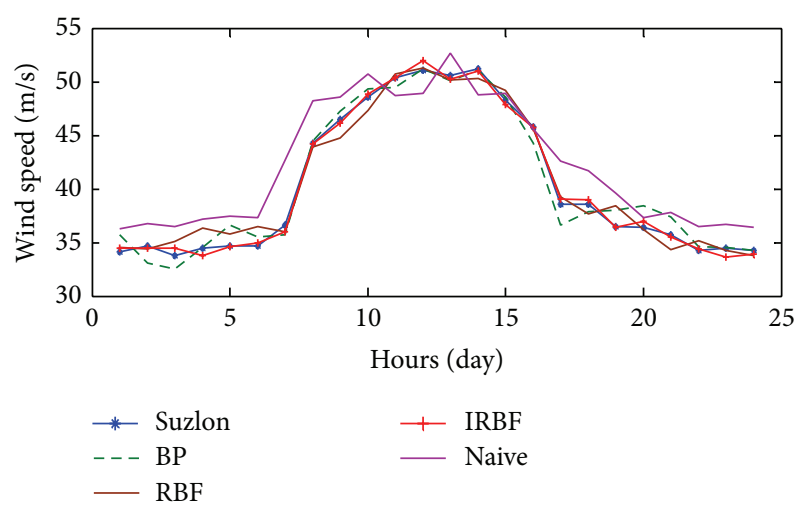

FIGURE 5: Comparison plot for wind speed predicted by various methods for a 24-hour horizon.

the wind power estimated using (11), from the wind speed predicted using various methods.

Based on the above experiments and results, the proposed IRBFN is proved to be a most suitable alternative for predicting the wind speed and thereby wind power. Thus, this network will be adopted for predicting the wind power for the DEDP for a practical power system. Next the DEDP solution methodology proposed in this research will be validated with a standard 10-unit test system.

7.2. Case 2: Validating the Hybrid TLBO-SQP Method for Solving DEDP. To validate the proposed hybrid TLBO-SQP method for solving the DEDP, this research adopts a 10-unit test system proven as a complex test bench for several solution methods. Also the results are compared with the very recent solutions reported in the literature [14]. Here the TLBO uses a population size of 100 and total generation of 10000 . A total number of 30 trials were performed on the test system using the proposed hybrid TLBO-SQP method to arrive at the final conclusions about the superiority of the proposed method for solving the DEDP with multiple fuel options. The results are compared with the chaotic self-adaptive differential harmony search algorithm (CSADHS) proposed in [14]. This research did not implement the CSADHS method but only compared the final results.

The system data and load demand considered for $24 \mathrm{~h}$ time interval is obtained from [2]. In this test case, the DEDP only considers valve-point effect in the fuel cost function of generators. The optimal generation cost obtained by the proposed hybrid TLBO-SQP method is $\$ 1018679.2135$ as against the $\$ 1018681.872$ produced by the CSADHS algorithm [14] for a $24 \mathrm{~h}$ scheduling horizon and the corresponding production cost for each hour in the horizon is given in Table 6. Table 7 shows the production cost distribution as best, worst, and average production cost obtained for 30 different trial runs. The convergence characteristic of the hybrid TLBO-SQP method is shown in Figure 6. From Figure 6, it is demonstrated that the convergence characteristic of the proposed hybrid TLBO-SQP method is reliable and better than TLBO alone. The standard deviation of generation cost obtained by the proposed TLBO-SQP method is at an average of 1.5 for 30 different trial runs, which is less compared to

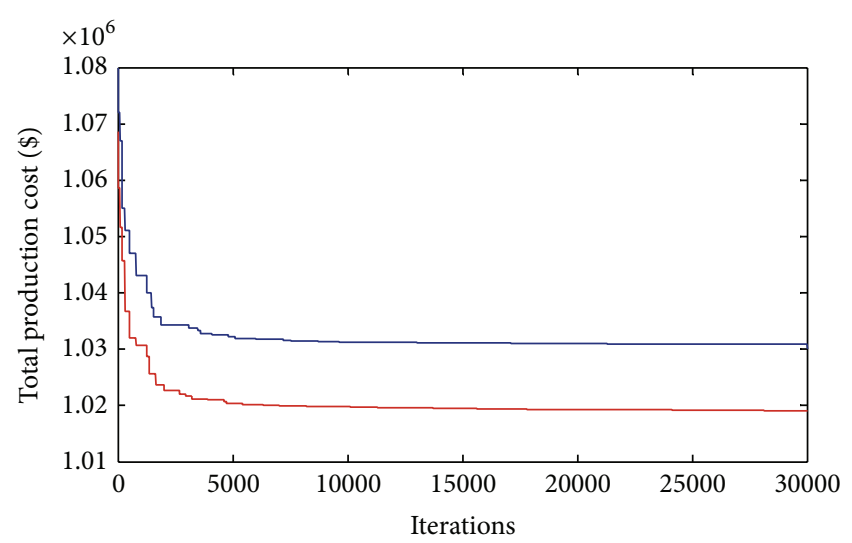

TLBO-SQP
TLBO

FIGURE 6: Convergence plot for both the methods for Case 2.

CSADHS algorithm, thus proving that the proposed method is consistent in reaching the best optimal solution and best suitable for solving the DEDP with valve-point effects.

7.3. Case 3: A practical 7-Unit Multifuel DEDP with Integrated Wind. This is a practical system where 7 thermal units are supplying the power demand and controlled by LDCE. During 2010, wind power generation is penetrated into the system with an installed capacity of $150 \mathrm{MW}$. As wind power is unpredictable, an improved RBFN is proposed to forecast the wind power and it is very well demonstrated through Case 1 that it is well suited for this system. The data for this practical system is given in Table 8 . Similarly power demand for the total scheduling horizon is given in Table 9. The wind power for this entire scheduling horizon is already forecasted and will be used from Table 5 rounded to integer as done in the LDCE. The remaining power demand (difference in Tables 9 and 5) will be scheduled using the proposed hybrid TLBOSQP method.

The optimal generation cost obtained by the proposed hybrid TLBO-SQP algorithm for $24 \mathrm{~h}$ time duration is $\$ 9538.1851$ as against the cost of 9736.1471 obtained using the TLBO method alone. The corresponding generation schedule by the hybrid TLBO-SQP method is shown in Table 10. As seen in Table 11, the TLBO-SQP method can obtain the better total fuel cost and best total fuel cost compared to TLBO method, thus resulting in the higher quality solution. Moreover, in all the 30 different trial runs, the TLBO-SQP method produced almost less total fuel costs, thus conforming a better quality solution and convergence characteristic. The reliability of the proposed method in producing quality solutions (total fuel cost less than the other methods and convergence characteristics) is above $90 \%$ (as per 30 different trial runs). The average computation time of the proposed TLBO-SQP algorithm for $24 \mathrm{~h}$ time duration is $2.53 \mathrm{~min}$ as against the $4.21 \mathrm{~min}$ taken by the TLBO method. The convergence characteristic is shown in Figure 7. From Figure 7, it is revealed that the convergence characteristic of the proposed hybrid TLBO-SQP algorithm is steady and 


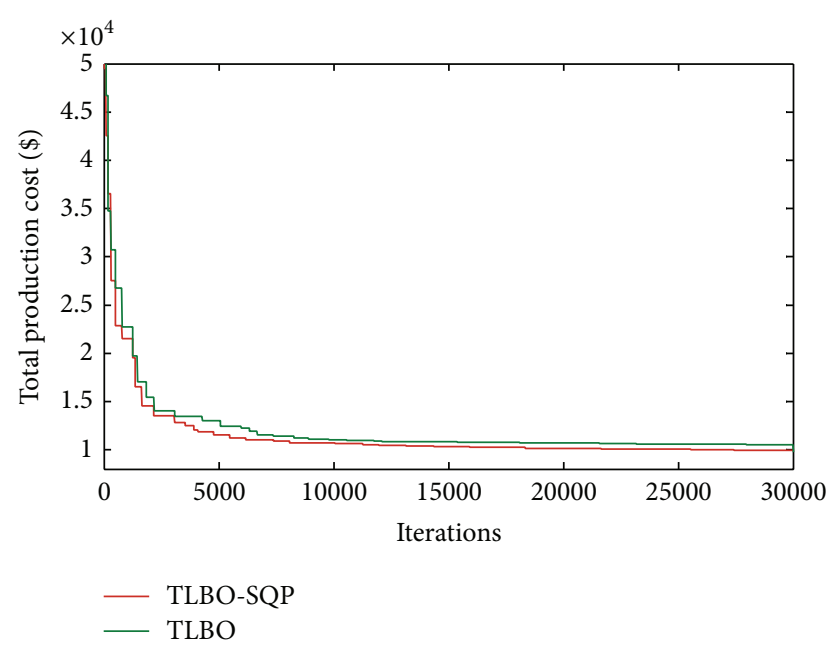

Figure 7: Convergence plot for both the methods for Case 3.

fast. The standard deviation of generation cost obtained by proposed hybrid TLBO-SQP algorithm and TLBO are 10.26 and 20.14, respectively. This proves that the proposed algorithm is consistent in reaching the best optimal solution for this practical 7-unit multiple fuel generating station.

\section{Discussion}

Due to fluctuation and nonlinearity of wind speed, accurate wind speed prediction plays a major role in operational control of wind farms. Thus, the radial basis function network, a class in artificial neural network, is used to develop architecture for predicting wind speed in wind farms. The evaluation of neural network architecture is carried out for various real time data from wind farm. The performance analysis of modeling frame work was useful for accurate wind speed prediction in wind farm operators and thereby improves the reliability of wind power. Thus, on a particular day the wind speed is predicted by training the network with different samples (the temperature, wind direction, and the past history of wind speed) but data taken for similar wind speeds at various instances. Thus, the predicted wind speed is almost similar to the actual wind speed.

After the wind power is estimated (from the predicted wind speed), the difference in power is dispatched using the practical 7-unit multiple fuel DEDP with valve-point effects. Based on the simulation results in Case 2, the hybrid TLBOSQP method is found suitable producing quality dispatch schedule. Hence, the hybrid TLBO-SQP is used to further dispatch 7-unit multiple fuel DEDP meeting the balance power demand.

The above 7-unit multiple fuel DEDP is considered only with valve-point effects in problem formulation. Several constraints like prohibited operating zones, line flows, voltage limits, and transmission losses will also be included in the problem formulation for better accuracy of the dispatch solution and this will be done once practical data is received from the power station.

\section{Conclusion}

Integration of wind power into thermal generation system and its impact on the DEDP are explored in this paper. The DEDP formulation considering valve-point effects and multiple fuel options has been solved using a new hybrid TLBO-SQP algorithm. The DEDP formulation also incorporated wind power to demonstrate and assess the economic benefits of integrating wind power into power system grids. The wind speed prediction method has been analyzed using a radial basis function network and trained using real time wind data with different samples taken for similar wind speeds. Simulation studies revealed that the RBFN is found to be a more reasonable predictor than the existing methods used in load dispatch center. Based on the predicted wind power, the hybrid TLBO-SQP algorithm is used to solve the DEDP to source the remaining power demand with the available thermal generation. The performance of the TLBO algorithm is studied on a standard bench mark DEDP with 10 units, in terms of the convergence rate and accuracy of the solution produced. SQP is used on the run to fine-tune the better solutions produced by the TLBO algorithm. The effectiveness of the TLBO-SQP is finally illustrated on a practical 7-unit multiple fuel DEDP with valve-point effects with practical data. The comprehensive numerical results reveal that the proposed wind speed predictor using $\mathrm{RBFN}$ and the hybrid TLBO-SQP method to solve DEDP are most suitable for a more economical power dispatch for practical systems.

\section{Nomenclature}

The following nomenclature will be used throughout this paper:

$F_{T}: \quad$ Total production cost $(\$)$

$F_{i h}\left(P_{i h}\right): \quad$ Incremental fuel cost function (\$/hr)

$P_{i h}$ : $\quad$ Real power output of the $i$ th unit at the $h$ th

interval (MW)

$N$ : $\quad$ Number of generating units

$N_{F}$ : fuel options for each unit

$H$ : $\quad$ Number of intervals in the given time

$P_{D h}: \quad$ Porizon $\quad$ Power demand at the $h$ th interval (MW)

$P_{\text {Loss }, h}: \quad$ Power Loss at the $h$ th interval (MW)

$B_{m n}: \quad$ Transmission loss coefficients

$P_{i h \text { min }} / P_{i h \text { max }}:$ Minimum/maximum limit of the real power of the $i$ th unit at the $h$ th interval (MW)

$U R_{i} / D R_{i}: \quad \quad U p /$ down ramp rate limits of the $i$ th unit (MW)

$P_{i h}^{0}: \quad \quad$ Previous power generated by the $i$ th unit at the $h$ th interval (MW)

$w_{R}: \quad$ Wind turbine rated power

$v: \quad$ Actual wind speed

$v_{R}: \quad$ Wind turbine rated wind speed

$v_{\text {in }}$ : Wind turbine cutin speed

$v_{\text {out }}: \quad$ Wind turbine cutout speed. 


\section{Conflict of Interests}

The authors declare that there is no conflict of interests regarding the publication of this paper.

\section{References}

[1] T. Jayabarathi and G. Sadasivam, "Evolutionary programmingbased economic dispatch for units with multiple fuel options," European Transactions on Electrical Power, vol. 10, no. 3, pp. 167$170,2000$.

[2] T. A. A. Victoire and A. E. Jeyakumar, "Deterministically guided PSO for dynamic dispatch considering valve-point effect," Electric Power Systems Research, vol. 73, no. 3, pp. 313-322, 2005.

[3] C.-L. Chiang, "Improved genetic algorithm for power economic dispatch of units with valve-point effects and multiple fuels," IEEE Transactions on Power Systems, vol. 20, no. 4, pp. 16901699, 2005.

[4] R. Balamurugan and S. Subramanian, "Hybrid integer coded differential evolution-dynamic programming approach for economic load dispatch with multiple fuel options," Energy Conversion and Management, vol. 49, no. 4, pp. 608-614, 2008.

[5] D. N. Jeyakumar, T. Jayabarathi, and T. Raghunathan, "Particle swarm optimization for various types of economic dispatch problems," International Journal of Electrical Power and Energy Systems, vol. 28, no. 1, pp. 36-42, 2006.

[6] J.-C. Lee, W.-M. Lin, G.-C. Liao, and T.-P. Tsao, "Quantum genetic algorithm for dynamic economic dispatch with valvepoint effects and including wind power system," International Journal of Electrical Power and Energy Systems, vol. 33, no. 2, pp. 189-197, 2011.

[7] G.-C. Liao, "A novel evolutionary algorithm for dynamic economic dispatch with energy saving and emission reduction in power system integrated wind power," Energy, vol. 36, no. 2, pp. 1018-1029, 2011.

[8] J. Jasper, R. S. Sivakumar, T. Victoire, and S. N. Deepa, "Cost Optimization of Power Generation Using a Differential Evolution Algorithm Enhanced with Neighbourhood Search Operation," International Review of Electrical Engineering, vol. 7, no. 5, pp. 5854-5865, 2012.

[9] M. Basu, "Hybridization of bee colony optimization and sequential quadratic programming for dynamic economic dispatch," International Journal of Electrical Power \& Energy Systems, vol. 44, no. 1, pp. 591-596, 2013.

[10] J. Park and I. W. Sandberg, "Approximation and radial-basisfunction networks," Neural Computation, vol. 5, no. 2, pp. 305316, 1993.

[11] G. N. Kariniotakis, G. S. Stavrakakis, and E. F. Nogaret, "Wind power forecasting using advanced neural networks models," IEEE Transactions on Energy Conversion, vol. 11, no. 4, pp. 762$767,1996$.

[12] K. G. Sheela and S. N. Deepa, "Performance analysis of modeling framework for prediction in wind farms employing artificial neural networks," Soft Computing, vol. 18, no. 3, pp. 607-615, 2014.

[13] D. Niu, Y. Wang, and D. D. Wu, "Power load forecasting using support vector machine and ant colony optimization," Expert Systems with Applications, vol. 37, no. 3, pp. 2531-2539, 2010.

[14] R. Arul, G. Ravi, and S. Velusami, "Chaotic self-adaptive differential harmony search algorithm based dynamic economic dispatch," International Journal of Electrical Power \& Energy Systems, vol. 50, pp. 85-96, 2013.
[15] R. V. Rao, V. J. Savsani, and D. P. Vakharia, “Teaching-learningbased optimization: a novel method for constrained mechanical design optimization problems," CAD Computer Aided Design, vol. 43, no. 3, pp. 303-315, 2011.

[16] R. V. Rao, V. J. Savsani, and D. P. Vakharia, “Teaching-learningbased optimization: an optimization method for continuous non-linear large scale problems," Information Sciences, vol. 183, pp. 1-15, 2012.

[17] P. T. Boggs and J. W. Tolle, "Sequential quadratic programming," in Acta Numerica, 1995, Acta Numerica, pp. 1-51, Cambridge University Press, Cambridge, UK, 1995.

[18] M. A. Mohandes, S. Rehman, and T. O. Halawani, "A neural networks approach for wind speed prediction," Renewable Energy, vol. 13, no. 3, pp. 345-354, 1998.

[19] A. Sfetsos, "A comparison of various forecasting techniques applied to mean hourly wind speed time series," Renewable Energy, vol. 21, no. 1, pp. 23-35, 2000.

[20] T. G. Barbounis, J. B. Theocharis, M. C. Alexiadis, and P. S. Dokopoulos, "Long-term wind speed and power forecasting using local recurrent neural network models," IEEE Transactions on Energy Conversion, vol. 21, no. 1, pp. 273-284, 2006.

[21] M. Monfared, H. Rastegar, and H. M. Kojabadi, "A new strategy for wind speed forecasting using artificial intelligent methods," Renewable Energy, vol. 34, no. 3, pp. 845-848, 2009.

[22] M. Lei, L. Shiyan, J. Chuanwen, L. Hongling, and Z. Yan, "A review on the forecasting of wind speed and generated power," Renewable and Sustainable Energy Reviews, vol. 13, no. 4, pp. 915-920, 2009.

[23] A. Costa, A. Crespo, J. Navarro, G. Lizcano, H. Madsen, and E. Feitosa, "A review on the young history of the wind power shortterm prediction," Renewable and Sustainable Energy Reviews, vol. 12, no. 6, pp. 1725-1744, 2008.

[24] E. Cadenas and W. Rivera, "Short term wind speed forecasting in La Venta, Oaxaca, México, using artificial neural networks," Renewable Energy, vol. 34, no. 1, pp. 274-278, 2009.

[25] T. Niknam, R. Azizipanah-Abarghooee, A. Roosta, and B. Amiri, "A new multi-objective reserve constrained combined heat and power dynamic economic emission dispatch," Energy, vol. 42, no. 1, pp. 530-545, 2012. 


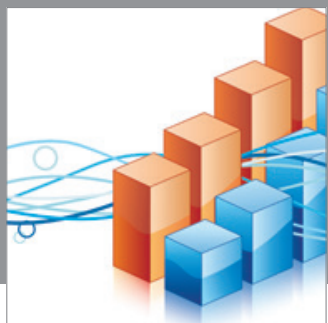

Advances in

Operations Research

mansans

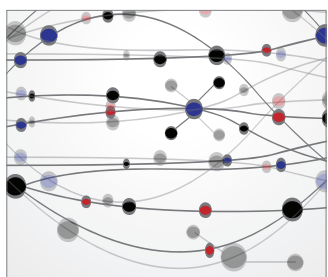

The Scientific World Journal
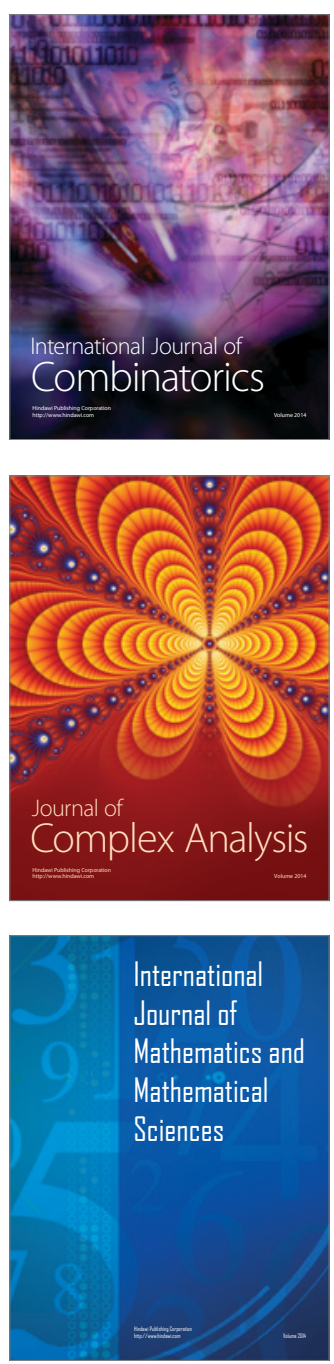
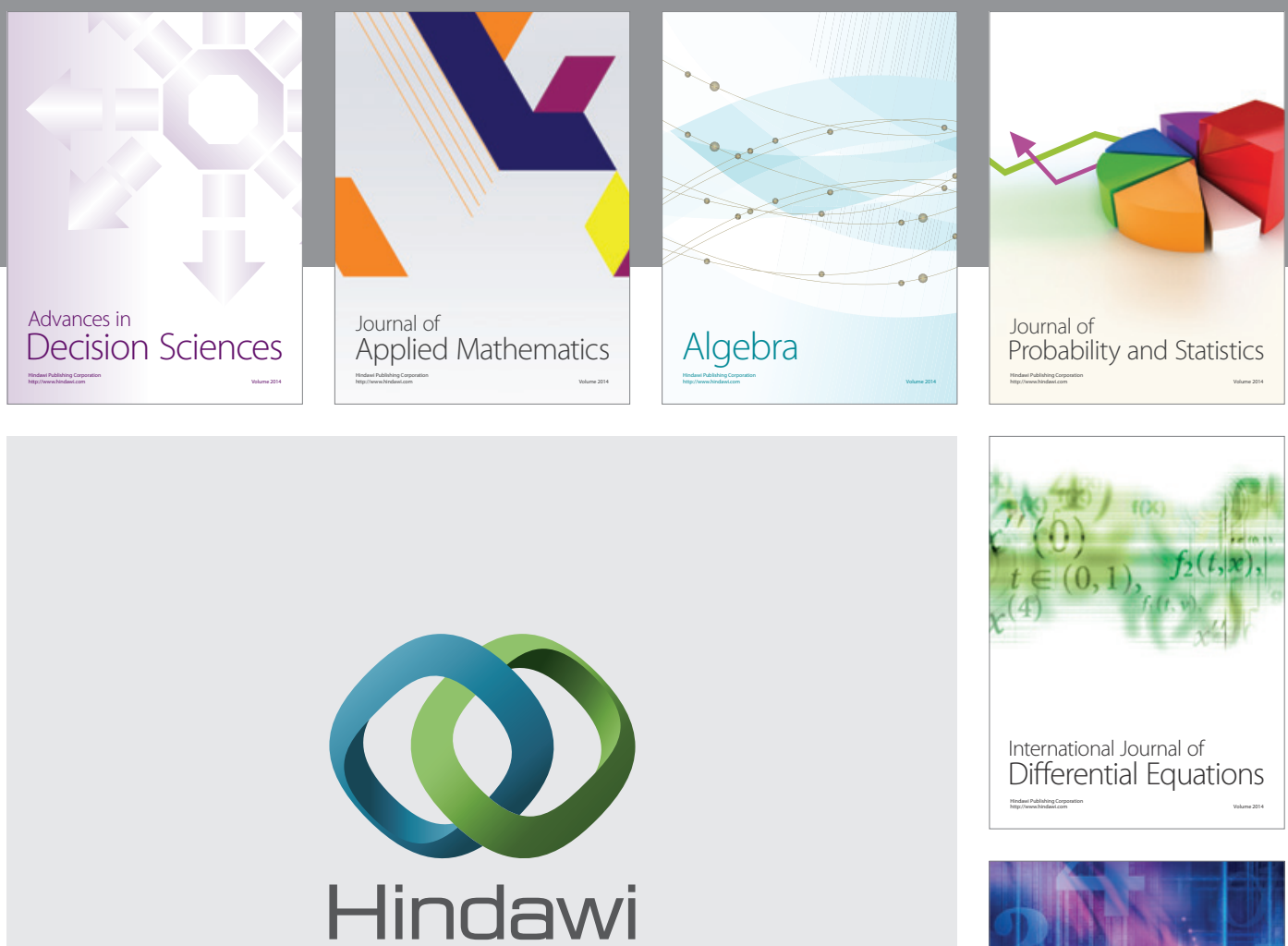

Submit your manuscripts at http://www.hindawi.com
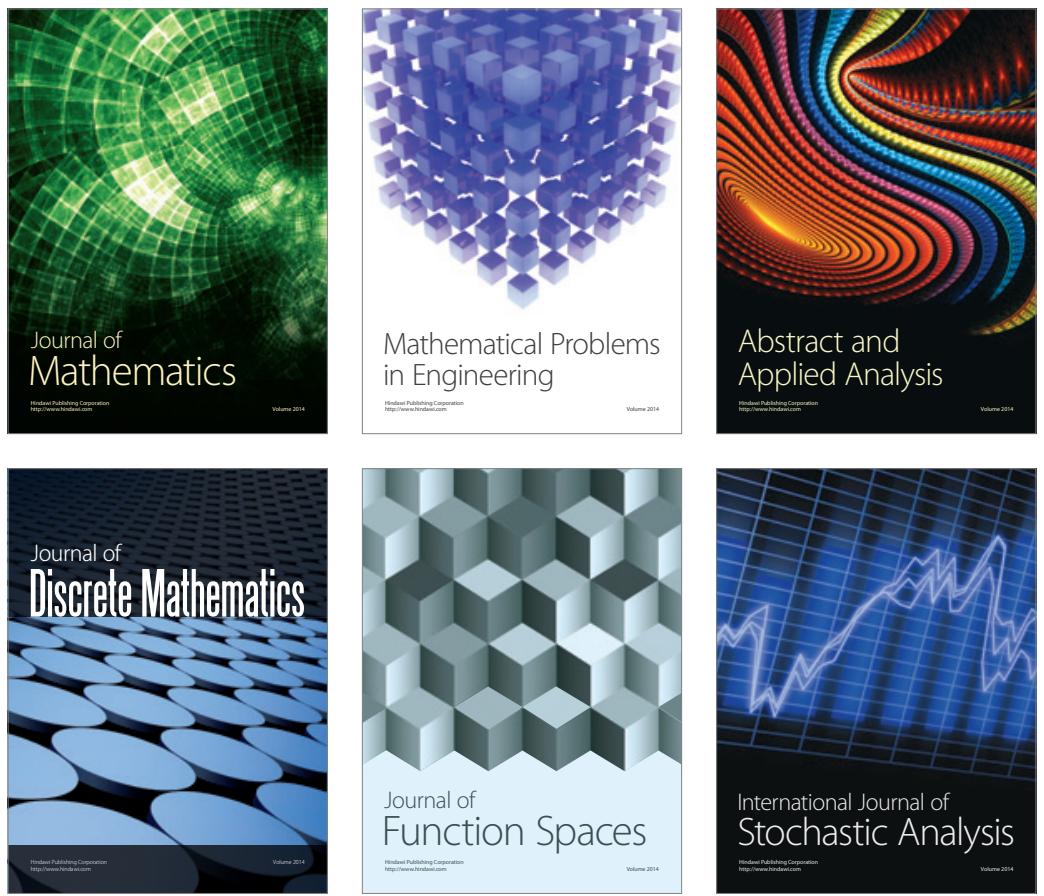

Journal of

Function Spaces

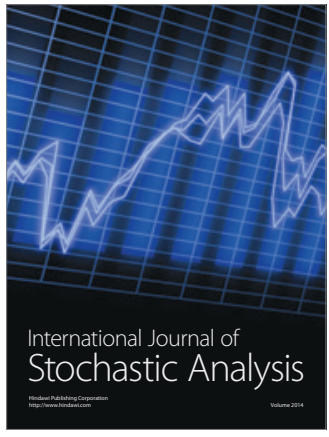

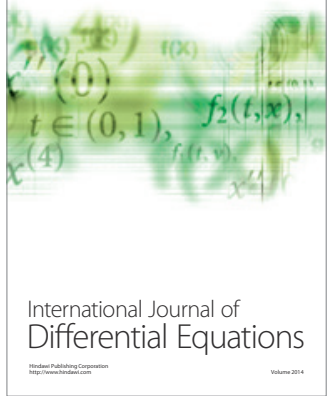
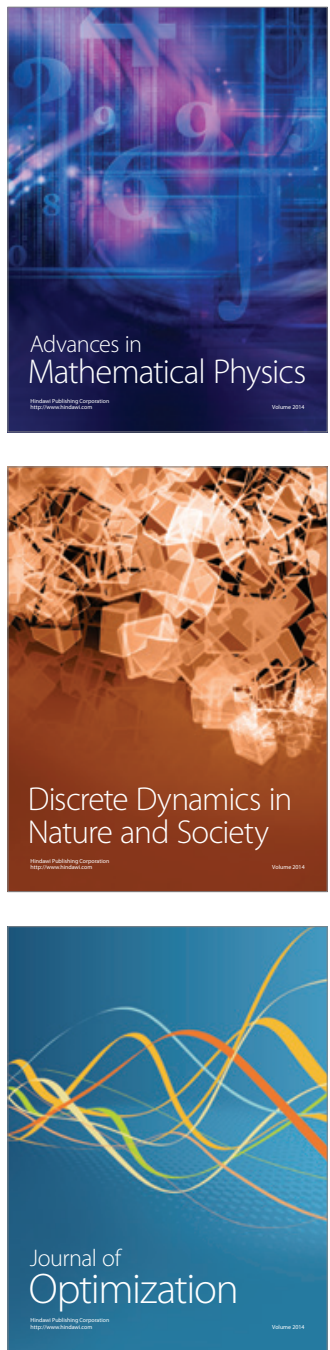